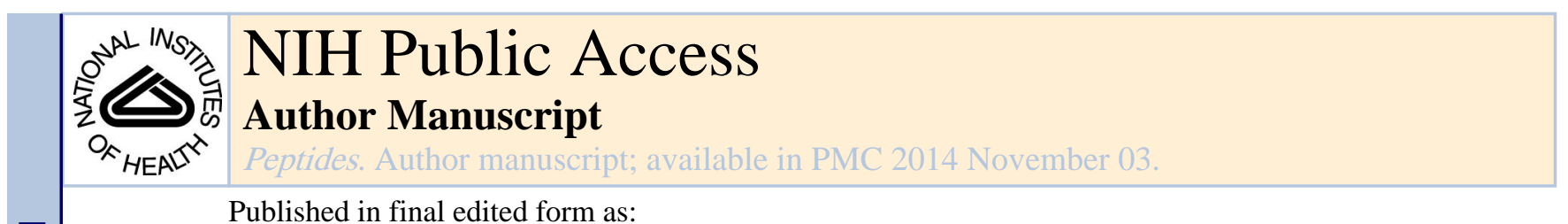

Published in final edited form as:

Peptides. 2013 November ; 49: 138-144. doi:10.1016/j.peptides.2013.09.009.

\title{
Ghrelin and peptide YY increase with weight loss during a 12- month intervention to reduce dietary energy density in obese women
}

\author{
Brenna R. Hill ${ }^{a}$, Barbara J. Rolls ${ }^{b}$, Liane S. Roe ${ }^{b}$, Mary Jane De Souza ${ }^{a}$, and Nancy I. \\ Williams $^{b}$ \\ aWomen's Health and Exercise Laboratory, Department of Kinesiology, Penn State University, \\ University Park, Pa 16802 \\ bLaboratory for the Study of Human Ingestive Behavior, Department of Nutritional Sciences, Penn \\ State University, University Park, Pa 16802
}

\begin{abstract}
Reducing dietary energy density (ED) promotes weight loss; however, underlying mechanisms are not well understood. The purpose of this study was to determine if low-ED diets facilitate weight loss through actions on ghrelin and peptide YY (PYY), independent of influences of psychosocial measures. Seventy-one obese women (BMI $30-40 \mathrm{~kg} / \mathrm{m}^{2}$ ) ages $22-60 \mathrm{y}$ received counseling to reduce ED. Fasting blood samples were analyzed for total ghrelin and total PYY by radioimmunoassay at mo $0,3,6$, and 12 . Restraint, disinhibition, and hunger were assessed by the Eating Inventory. Body weight $(-7.8 \pm 0.5 \mathrm{~kg})$, BMI $\left(-2.9 \pm 0.2 \mathrm{~kg} / \mathrm{m}^{2}\right)$, body fat $(-3.0 \pm 0.3 \%)$, and $\mathrm{ED}(-0.47 \pm 0.05 \mathrm{kcal} / \mathrm{g}$ or $-1.97 \pm 0.21 \mathrm{~kJ} / \mathrm{g})$ decreased from mo 0 to $6(\mathrm{p}<0.05)$ after which no change occurred from mo 6 to 12. Ghrelin increased in a curvilinear fashion (mo 0: $973 \pm 39$, mo 3: $1024 \pm 37$, mo 6: $1109 \pm 44$, and mo 12: $1063 \pm 45 \mathrm{pg} / \mathrm{ml}, \mathrm{p}<0.001)$ and PYY increased linearly (mo 0: $74.2 \pm 3.1$, mo 3: $76.4 \pm 3.2$, mo 6: 77.2 \pm 3.0 , mo 12: $82.8 \pm 3.2 \mathrm{pg} / \mathrm{ml}, \mathrm{p}<0.001$ ). $\mathrm{ED}$, body weight, and hunger predicted ghrelin, with ED being the strongest predictor (ghrelin = $2674.8+291.6 \times \mathrm{ED}-19.2 \times \mathrm{BW}-15 \times \mathrm{H} ; \mathrm{p}<0.05)$. There was a trend toward a significant association between ED and PYY (PYY $=115.0-43.1 \times \mathrm{ED} ; \mathrm{p}=0.05)$. Reductions in ED may promote weight loss and weight loss maintenance by opposing increases in ghrelin and promoting increases in PYY.
\end{abstract}

\section{Keywords}

ghrelin; peptide YY; dietary energy density; weight loss

\footnotetext{
(C) 2013 Elsevier Inc. All rights reserved.

Corresponding Author: Nancy I. Williams, Sc.D., 276 Recreation Building, Penn State University, University Park, PA 16802, Phone: 814-863-1163, Fax: 814-865-1275, niw1@psu.edu.

Disclosure: The authors have nothing to disclose. All authors have approved the final submitted manuscript.

Publisher's Disclaimer: This is a PDF file of an unedited manuscript that has been accepted for publication. As a service to our customers we are providing this early version of the manuscript. The manuscript will undergo copyediting, typesetting, and review of the resulting proof before it is published in its final citable form. Please note that during the production process errors may be discovered which could affect the content, and all legal disclaimers that apply to the journal pertain.
} 


\section{Introduction}

Dietary energy density (ED; $\mathrm{kcal} / \mathrm{g}$ or $\mathrm{kJ} / \mathrm{g}$ ) can be reduced by decreasing the proportion of fat or by increasing the water content of foods [22, 47]. Several studies [5, 6, 48] have demonstrated that humans tend to consume a consistent weight or volume of food from day to day. Thus, consuming a low-ED diet can reduce energy intake while maintaining the volume of food eaten. Decreasing dietary ED has been shown to be useful in long-term weight loss $[8,19,24,36,45]$; however, the underlying physiological mechanisms remain to be elucidated.

Ghrelin is an orexigenic hormone secreted into the blood from the X/A-like cells in the stomach and duodenum $[16,30]$. Circulating ghrelin increases with weight loss in normal weight women $[37,38]$, whereas concentrations are suppressed and normalized (increased) with weight loss in obese individuals [25]. PYY is a satiety hormone secreted from L-cells in the distal gut where it slows digestion to increase absorption of nutrients [56]. PYY concentrations are suppressed and increased energy intake is needed to stimulate equivalent PYY secretion in obese individuals in comparison to normal weight counterparts [34]. With weight loss, circulating PYY does not necessarily return to concentrations observed in normal weight counterparts. Some studies have demonstrated increases $[28,33]$ whereas others have observed decreases [21, 46, 55] or no change [51] in PYY in response to weight loss. The current study adds to the literature on the role of PYY in weight loss.

Ghrelin and PYY may be related to psychosocial measures of eating behaviors such as dietary restraint (tendency to consciously restrict food intake to control body weight) [50, 52], disinhibition (loss of control over eating in response to emotional or social cues) [10, 41], and tendency toward hunger [32]. For example, higher circulating ghrelin has been associated with high dietary restraint in obese individuals [52] and higher scores for hunger independent of BMI in a large population of normal weight individuals [32]. These studies have begun to relate behavioral to physiological measures; however, interactions between these factors have not been determined. It is attractive to posit that altered physiological states, such as suppressed concentrations of PYY, may be modulating behavioral changes, such as increases in dietary restraint, to offset biological abnormalities that may influence meal-related hunger and satiety.

Specifically, only one study has examined the association between dietary ED and key gut hormones involved in food intake regulation such as ghrelin and PYY [29]. As well, other studies have been designed to assess the impact of variables such as meal volume [44] and gastric distention [59] on these same gastrointestinal hormones and have thus, altered the ED of test meals; however, these studies were not designed to focus on the impact of chronic alterations in ED on hormonal outcomes and consequently, assessment of ED as a physiological variable that could impact hormonal outcomes was not quantified or analyzed to determine if ED impacted hormonal outcomes independently.

The current study is an extension of a previous year-long clinical trial in which obese women received instruction in reducing dietary ED to promote weight loss [19]. Dietary ED was a significant predictor of body weight during the weight loss phase of the trial. Blood 
samples collected during the trial provided an opportunity to investigate how physiological mechanisms such as changes in gut hormones in response to modifications in dietary ED may promote weight loss and weight maintenance. Additionally, we sought to determine if the impact of ED on gut hormone concentrations remains significant when accounting for changes in psychosocial variables. Thus, the purpose of this study was to determine whether low-ED diets might facilitate weight loss through actions on circulating concentrations of ghrelin and PYY, independent of the influence of psychosocial measures. We hypothesized that: 1) ghrelin would increase in accordance with weight loss, but that low-ED diets would be associated with lower circulating concentrations of ghrelin, 2) PYY would decrease in response to weight loss as a compensatory mechanism to regain weight, and 3) associations between ghrelin and ED would be independent of the influence of psychosocial variables.

\section{Materials and Methods}

\subsection{Study Protocol and Participants}

This study is secondary analysis of data from a randomized clinical trial that assessed the effect of reducing dietary ED as a weight loss strategy in obese women [19] (NCT ID: 00108784). Inclusion in the study was based upon the following criteria: 1) women ages 20 -60 years 2) body mass index (BMI) between $30-40 \mathrm{~kg} / \mathrm{m}^{2}$. Exclusion was based upon the following criteria: 1) blood pressure $>140 / 90 \mathrm{mmHg}$ 2) serum triacylglycerols $>400 \mathrm{mg} / \mathrm{dL}$ 3) total cholesterol $>90^{\text {th }}$ percentile for age 4) the presence of medical conditions that precluded participation or condition limiting physical activity 5) pregnancy/lactation 6) taking selective serotonin reuptake inhibitors 7) symptoms of depression or disordered eating 8) currently participating in a weight loss program. All participants signed an informed consent to participate. The protocol was approved by the Institutional Review Board of The Pennsylvania State University.

Participants in the clinical trial were randomly assigned to one of two intervention groups. One group was counseled on reducing dietary fat intake to decrease the ED of their diet, and the second group was advised to increase their intake of water-rich foods such as fruits and vegetables in addition to reducing fat intake. The trial consisted of two phases: in the weight loss phase (months 0 to 6 ), participants attended weekly counseling sessions with a dietitian and in the weight maintenance phase (months 6 to 12), participants attended one monthly group session and one monthly individual session with a dietitian. Although the two intervention groups were counseled on different strategies to reduce ED, all participants significantly reduced dietary ED and lost a substantial amount of weight during the trial [19]. As well, circulating concentrations of total ghrelin and total PYY at all time points (month 0,3,6 and 12), analysis of which were main outcome measures of the current study, were not significantly different between the two original study groups. Thus, for the purpose of characterizing hormones in the current study, the data from participants in both intervention groups who completed the year-long trial were combined for analysis.

\subsection{Intervention}

The main objective for the intervention was to reduce dietary ED in free-living obese women to determine the effect of low-ED diets on weight loss and weight loss maintenance. 
Participants were advised to reduce fat intake and increase intake of water-rich foods, especially fruit and vegetables. Registered dietitians led counseling sessions where participants were taught to choose foods lower in ED and appropriate in portion size. No counseling was provided on energy restriction and participants were instructed to eat ad libitum amounts of food while following the principles of the diet.

2.2.1. Phase 1-Details regarding the original clinical trial have been previously published [19]. Briefly, to achieve a reduced-fat diet, participants were provided educational materials in regard to cooking/recipe modifications, grocery shopping and dining-out strategies. Participants were taught recommended serving sizes, appropriate portion sizes and were instructed to increase water-rich foods like fruits, vegetables, and soups. They were encouraged to eat larger, satisfying portions of low-ED foods and recommended serving sizes of medium- and high-energy density foods. Participants were also provided behavior therapy recommendations based on social cognitive theory [3].

2.2.2. Phase 2-Phase 2 of the study occurred during months 6 through 12 . Throughout phase 2 participants met to review material presented during phase 1 . Group lessons led by dietitians were comprised of 6 topics: holiday eating, cooking and recipe modification, appropriate portion sizes, label reading, dining out, and grocery shopping. During monthly individual sessions, dietitians met with participants to review 3-day diet records and discuss any questions or concerns.

\subsection{Assessment of study outcomes}

2.3.1. Diet Composition-Participants attended one training session at the beginning of the study for instruction on recording foods and beverages. Participants completed detailed three-day diet records for two weekdays and one weekend day at each of the four time points. Dietitians reviewed diet records with the participants to promote completeness and accuracy. The diet records were analyzed by the Diet Assessment Center at The Pennsylvania State University using the Nutrition Data System for Research (Nutrition Coordinating Center, University of Minnesota, Minneapolis, MN). The analysis of energy intake data and detailed calculation of dietary ED and fruit and vegetable intake have been previously described [19].

2.3.2. Changes in body weight and body composition-Participants were weighed to the nearest $0.1 \mathrm{~kg}$ without shoes and while wearing light clothing on a calibrated scale. Although body weight was measured frequently during the trial, for comparison with the satiety hormone data, the present analyses include only the weights measured at months 0,3 , 6 , and 12 . Height to the nearest $0.5 \mathrm{~cm}$ was measured at month 0 and confirmed at month 6 . Body composition measures were obtained at months $0,3,6$, and 12 . Body fat percentage (within $0.1 \%$ ) was measured by using bioelectrical impedance (Biodynamics model 310; Biodynamics Corporation, Seattle, WA) after a 12-hour fast and 48-hour abstinence from alcohol.

2.3.3. Blood Sampling Procedures-Participants arrived at the laboratory fasted ( 12 hours) and abstinent from alcohol ingestion (48 hours). Blood samples were obtained by 
laboratory trained personnel between 0700 and 1000 hours at months $0,3,6$, and 12 of the study. Approximately 28 milliliters $(\mathrm{mL})$ were collected by venipuncture at month 0 and $13.5 \mathrm{~mL}$ at all other time points. Serum samples were aliquoted to $2 \mathrm{~mL}$ microtubes and stored at $-80^{\circ} \mathrm{C}$ until analysis. All samples from a given participant were included in the same assay.

2.3.4. Ghrelin and PYY Analysis-Serum sample analysis consisted of assaying fasting blood samples for gut hormones at each time point: $0,3,6$, and 12 months. Ghrelin was assayed using a radioimmunoassay (RIA) for total ghrelin ( $\mathrm{pg} / \mathrm{ml}$ ) (GHRT-89HK; Millipore, Billerica, MA). The sensitivity of the assay is $93 \mathrm{pg} / \mathrm{mL}$ and the intra- and inter-assay coefficients of variation were $10.0 \%$ and $14.7 \%$, respectively. PYY was assayed using an RIA for total PYY (pg/ml) (PYYT-66HK; Millipore, Billerica, MA). The sensitivity of the assay is $10 \mathrm{pg} / \mathrm{mL}$ and the intra- and inter-assay coefficients of variation were $9.4 \%$ and $8.5 \%$, respectively. Samples were assayed in duplicate and all samples from a given participant were assayed within the same kit.

2.3.5. Psychosocial Factors-Participants completed the Eating Inventory [54] at months 0,6 , and 12 to measure dietary restraint (the tendency to consciously restrict food intake to control body weight), disinhibition (the loss of control over eating in response to emotional or social cues), and tendency toward hunger (the degree of subjective feelings of hunger).

2.3.6. Visual Analogue Scales-Hunger and fullness were rated immediately before and after each meal (breakfast, lunch, and dinner) on the first day that participants completed diet records using a100-mm visual analogue scales (VAS). For example, hunger was assessed with the question "How hungry did you feel today?". The scale was anchored on the left by "not at all hungry" and on the right by "extremely hungry." Participants also rated daily hunger and fullness 1.5 hours after their evening meal on each of the three days that the participants completed their diet records to obtain a 3-day mean.

\subsection{Statistical Analysis}

Prior to analysis, the data for ghrelin and PYY were tested for outlying values using boxplot analyses. Extreme outliers represented a value more than 3 times the inter-quartile range (Q3-Q1) from the upper $(\mathrm{Q} 3)$ or lower $(\mathrm{Q} 1)$ quartile. Only observations that were determined to be extreme outliers were excluded from analyses. For ghrelin, 3 observations (1 observation at month 3 and 2 observations at month 12) were excluded from 2 participants, and for PYY, one observation was excluded from one participant at baseline.

Data were screened for age-related differences in ghrelin and PYY as participants included in the current analysis were of a wide age range ( $22-60$ years). Pearson correlation analyses between age and ghrelin and PYY concentrations at month 0 were performed. Additionally, participants were divided into two groups to determine if hormone concentrations vary with age: one group including participants above the median age of menopause (51 years) [39, 42] and one group including participants below the median age of menopause. In support, one study demonstrated no difference in PYY concentrations during

Peptides. Author manuscript; available in PMC 2014 November 03. 
fasting or subsequent to intraduodenal infusions of a glucose or lipid solution between individuals in two groups, one in which ages ranged from $65-80$ years and a second group in which individuals ranged from $20-34$ years [40].

A linear mixed-effect model with repeated measures using a random coefficients approach was employed to determine if changes in individual outcome variables were significant over time. Time (study month) was included as a continuous covariate in the model. The month 0 value was considered to be the first repeated measurement in the model. Quadratic and cubic factors of time were tested and included if they were significant [9]. The random coefficients model accounts for the correlation of the repeated measures within participants by allowing the intercept and longitudinal response to vary randomly for each individual; thus a response curve is generated for each subject [9]. The outcomes of body weight, body composition, ED and its components (energy in kcal and weight of food in $\mathrm{g}$ ) as well as circulating concentrations of total ghrelin and total PYY were characterized individually across all four time points.

For the main outcome variables of ghrelin and PYY we also evaluated several variables to determine significant predictors of these hormones over time by including in the statistical model measures of dietary intake, body weight and psychosocial variables [9]. Variables that were found to have significant bivariate correlations with main outcome variables (ghrelin and PYY) across the intervention or those that have been previously reported to be associated were tested as covariates in a stepwise manner in the random coefficients model.

Post-hoc analysis to determine which variables accounted for most of the variance in ghrelin included calculating predicted outcome variable values of the full model followed by calculations of predicted values of reduced models (full model when removing one significant predictor variable from the model at a time). The sum of squares for the full model and each of the reduced models was calculated. The change in the sum of squares from the full to each of the reduced models was compared to determine the variance accounted for by the removed variable [18]. A p-value $<0.05$ was considered statistically significant. Data are reported as mean \pm SEM and all analyses were performed using SPSS software (Version 18.0; Chicago, IL).

\section{Results}

\subsection{Participants}

Participant characteristics at month 0 of the intervention are presented in Table 1.

Participants were obese women ranging in age from 22 to 60 years. Seventy-one participants completed the original trial and were included in the current analysis.

\subsection{Trial Outcomes}

3.2.1. Energy Density and Energy Intake-Dietary ED decreased significantly across the intervention, as did each of its components: energy intake and food weight (Table 2). The random coefficients analysis found that ED followed a curvilinear relationship over time $\left(\mathrm{ED}=1.76-0.15 \times\right.$ month $+0.01 \times$ month $\left.^{2} ; \mathrm{p}<0.001\right)$. ED, energy intake and food 
weight decreased significantly from month 0 to month 3 ( $p<0.001$ for all), after which no significant change occurred from month 3 to month 12 ( $p>0.05)$.

3.2.2. Body weight and Body Composition-Analysis of body weight at the four selected time points showed significant decreases across the intervention (Table 2), consistent with the findings reported previously for the two subject groups. The random coefficients analysis found that body weight followed a curvilinear relationship over time (Weight $=90.4-2.1 \times$ month $+0.13 \times$ month $^{2} ; \mathrm{p}<0.001$ ). Table 2 illustrates that significant changes also occurred in other body composition parameters. The random coefficients model demonstrated that body weight $(\mathrm{kg})$, body fat $(\mathrm{kg})$, percent body fat, and BMI $\left(\mathrm{kg} / \mathrm{m}^{2}\right)$ decreased significantly from month 0 to month 6 of the intervention $(\mathrm{p}<$ 0.001). From months 6 to 12 of the intervention, there was a trend toward a significant increase in body weight $(\mathrm{p}=0.050)$; however, body weight at month 12 remained significantly lower than at month $0(\mathrm{p}<0.001)$.

3.2.3. Ghrelin-Figure $1 \mathrm{~A}$ illustrates fasting concentrations of total ghrelin at months 0,3 , 6 , and 12 of the intervention. Ghrelin exhibited a significant quadratic curvilinear relationship over time $\left(\right.$ ghrelin $=967+33.0 \times$ month $-1.93 \times$ month $\left.^{2} ; \mathrm{p}<0.001\right)$. The mean concentration of ghrelin increased from $973 \pm 39 \mathrm{pg} / \mathrm{ml}$ at month 0 to $1109 \pm 44 \mathrm{pg} / \mathrm{ml}$ at month 6 , a mean increase of $134 \pm 20 \mathrm{pg} / \mathrm{ml}$ or $14 \%$. Between months 6 and 12, there were no significant changes in ghrelin.

Significant predictors of ghrelin concentrations across the intervention are presented in Table 3. No significant correlations were detected between age and ghrelin at month 0 and no differences were detected in ghrelin or PYY concentrations between participants above or below the median age of menopause and thus, age was not included as a covariate in the model to predict ghrelin. ED was a significant predictor of ghrelin when the statistical model included only ED as a sole independent predictor as well as when ED was included in the full statistical model that included variables known to be associated with ghrelin (full model included energy density, body weight, hunger, dietary restraint, and PYY). Post-hoc analysis comparing the change in the sum of squares between the full and reduced models revealed that ED was the strongest predictor of ghrelin, such that participants with diets lower in ED had lower circulating concentrations of ghrelin. Body weight and the Eating Inventory score for hunger were both significant negative predictors of ghrelin. The dietary restraint score was not found to be a significant predictor of ghrelin.

3.2.4. PYY - Figure 1B illustrates fasting concentrations of total PYY at months $0,3,6$, and 12 of the intervention. In contrast to the curvilinear changes in body weight, PYY increased linearly over the trial. The random coefficients model for PYY illustrated a significant linear relationship of PYY over time (PYY $=74.1+0.67 \times$ month; $p=0.002)$. The mean concentration of PYY increased from $74.2 \pm 3.1 \mathrm{pg} / \mathrm{ml}$ at month 0 to $82.8 \pm$ $3.2 \mathrm{pg} / \mathrm{ml}$ at month 12 , a mean increase of $8.6 \pm 2.3 \mathrm{pg} / \mathrm{ml}$ or $11.6 \%$.

No significant correlations were detected between age and PYY at month 0 and no differences were detected in ghrelin or PYY concentrations between participants above or below the median age of menopause and thus, age was not included as a covariate in the 
model to predict PYY. There was a trend toward a significant association between dietary ED and PYY ( $p=0.05)$, which was the only predictor included the model (full model included energy density, ghrelin, BMI, dietary restraint, disinhibition, hunger, and fruit and vegetable intake) that was associated with changes in PYY across the intervention (Table 3). The relation between ED and PYY was negative, such that diets lower in ED were associated with higher total circulating PYY. Reported fruit and vegetable intake exhibited a trend $(\mathrm{p}=0.07)$ toward a significant negative association with PYY. Body mass index and the scores for dietary restraint and disinhibition were not found to be significant predictors of PYY.

3.2.5. Psychosocial Variables-Table 2 illustrates changes that occurred in Eating Inventory scores for dietary restraint, disinhibition, and hunger. Analysis found that these scores exhibited significant quadratic curvilinear relationships over time $(\mathrm{p}<0.001)$. Scores for dietary restraint increased from month 0 to month $6(\mathrm{p}<0.001)$ after which there was a trend toward a significant decrease from month 6 to $12(p=0.06)$. In contrast, scores for disinhibition and hunger decreased from month 0 to month 6 (p < 0.001$)$. No change was observed in scores for disinhibition and hunger from month 6 to $12(\mathrm{p}>0.05)$ and scores at month 12 remained significantly lower than month 0 ( $\mathrm{p}<0.05)$. When considering the prediction of ghrelin by ED, ED remained a significant positive predictor of ghrelin when psychosocial variables were included in the statistical model. In addition to ED, which was the strongest predictor, the score for hunger was also a significant predictor of ghrelin (Table 3). No psychosocial variables were significant predictors when included in the statistical model predicting changes in PYY. Thus, ED alone had the strongest influence on PYY (Table 3).

3.2.6. Visual Analogue Scales-Post-dinner hunger ratings increased significantly from month 6 to $12(\mathrm{p}=0.03)$; however, from month 3 to 6 hunger had decreased and the increase in hunger from month 6 to 12 was not significantly different from that observed at months 0 and 3. No other significant changes were observed in either hunger or fullness as measured by the 3 day mean of post-dinner hunger ratings or 3-meal AUC across the intervention (Table 2). As well, no significant associations were observed between VAS measures of appetite and ghrelin or PYY and thus, these variables were not included in the mixed-effects modeling analyses.

\section{Discussion}

Results of this study suggest that low-ED diets are associated with a hormonal milieu that likely facilitates long-term weight loss and weight loss maintenance. Specifically, low-ED diets were associated with lower circulating concentrations of ghrelin as well as a trend toward higher circulating concentrations of PYY. The association between ED, ghrelin, and PYY persisted when accounting for psychosocial measures of eating behavior. To our knowledge, this is the first study to examine the effect of low-ED diets on alterations in gastrointestinal hormone profiles during chronic weight loss and weight loss maintenance. Only one other study has examined the association between dietary ED and ghrelin and PYY [29]. These authors demonstrated no impact of ED on postprandial circulating ghrelin, but a high ED meal elicited increases in PYY only during the postprandial time period. 
Elevations in PYY may have been observed because of higher caloric or dietary fat content of the high ED meal, both of which are known to stimulate PYY release [1, 2]. As well, this study was designed to test a single meal and not the impact of chronic alterations in ED on hormonal outcomes and thus, our study provides a unique perspective on hormonal outcomes in response to chronic changes in ED and associated body weight loss.

Ghrelin is, to date, the only known "hunger hormone" and its role in both short- and longterm energy balance has been well characterized [13-15, 20, 37, 38, 43, 58]. Weight loss has consistently been shown to result in elevations in circulating concentrations of fasting as well as pre- and postprandial ghrelin in both lean [37, 38] and obese participants [15]. As expected in the present trial, circulating concentrations of ghrelin increased in response to weight loss during the 12-month intervention. Though increases in ghrelin were observed, our results indicated an association between ED and ghrelin such that diets lower in ED were associated with lesser increases in circulating concentrations of ghrelin during periods of both weight loss and weight maintenance. This association was evident even when accounting for psychosocial variables that have been identified as having an impact on ghrelin [32]. Thus, low-ED diets may be promoting weight loss and weight maintenance by blunting increases in circulating concentrations of ghrelin in response to weight loss. However, mechanisms underlying the effect of low-ED diets on the attenuation of increases in ghrelin usually associated with weight loss require further investigation.

The role of PYY in relation to changes in body weight remains unclear, as some studies have shown PYY decreases in response to weight loss [21, 46, 55], whereas others have shown increases [28, 49] or no change [51]. Our results indicate that PYY increased linearly during periods of both weight loss and weight maintenance in obese women who were following a lowED diet. We also found that there was a trend toward a significant association between dietary ED and PYY over time. This finding suggests that low-ED diets may promote increases in circulating concentrations of PYY during a period of weight loss and subsequent weight maintenance and even when circulating concentrations of ghrelin are increasing. Though, speculation with regard to the physiological association between lowED diets and PYY should be interpreted cautiously as the detected association did not achieve statistical significance.

It is interesting to postulate that the observed increase in PYY across our intervention, may be related to the properties of ED. PYY has traditionally been characterized as having a positive association with energy intake and particularly the macronutrients of fat and protein $[4,26]$. Participants in the current trial decreased energy as well as dietary fat intake [19]. Consequently, dietary ED may be one important and unique factor involved in the modulation of PYY. PYY is believed to be involved in the slowing of gastric emptying and gastric acid secretion [1]. Our data exhibited a trend toward a significant association between low-ED diets and increases in PYY over an entire year and thus, one possible mechanism through which lowED diets may promote chronic weight loss and weight maintenance is through promoting increases in PYY and consequent decreases in gastric acid secretion and emptying which may lead to meal cessation and perhaps, postprandial satiety [7]. However, these results should be interpreted carefully as the current study was not designed to measure gastric acid secretion or emptying and thus, one can only speculate 
with regard to the impact of changes in PYY on meal cessation and satiety. Additionally, no significant predictors of PYY other than ED were detected in our statistical model.

Consequently, it may be that other factors not measured in the current study impact changes in PYY in response to the dietary modification and weight loss observed herein.

Previously, it has been demonstrated that psychosocial variables such as dietary restraint, disinhibition, and hunger may impact circulating concentrations of ghrelin [32] and PYY [41]. We have demonstrated that scores for dietary restraint increased whereas both disinhibition and hunger decreased in response to a low-ED diet designed to induce weight loss. The changes in these psychosocial variables may have contributed to the weight loss observed; however, the current study suggests that ED may be impacting weight loss through its actions on ghrelin and PYY even when accounting for changes in psychosocial variables. ED was the strongest predictor of changes in ghrelin, more so than scores for hunger, suggesting that low-ED diets may promote lesser increases in circulating concentrations of ghrelin in response to weight loss. This association also suggests that lowED diets may counteract changes in subjective feelings of hunger that are typically a consequence of elevated concentrations of ghrelin. These associations do not show causality and studies are needed to further address the mechanisms underlying the inter-relationships of ghrelin and PYY with psychosocial variables during weight loss and maintenance.

Strengths of this study are several-fold. The sample size was larger than most studies that analyze gastrointestinal hormones in response to changes in body weight. Additionally, many studies show short-term effects on weight loss with no follow up to determine if weight re-gain occurs. The current study shows prospective data where participants lost weight and maintained the weight loss through an entire year. Lastly, ED was calculated from three-day diet records excluding beverages, which tend to have a lower ED than most foods and as such, the inclusion of beverages may disproportionately influence the calculation of ED [35].

One limitation of the study was the assessment of fasting concentrations of gut hormones as opposed to measurement of prandial events; however, we have shown in previously published data, that fasting concentrations of ghrelin and PYY are associated with the areas under the curve and 24-hour mean concentrations for each of these hormones [27, 37].

Consequently, the changes observed in the fasting concentrations of ghrelin and PYY in the current study may be related to changes in 24-hour profiles. Also, the measurement of total PYY and total ghrelin includes both circulating forms, $\mathrm{PYY}_{1-36}$ and PYY $3-36$ and des-acyl and acylated ghrelin, respectively. Though $\mathrm{PYY}_{3-36}$ and acylated ghrelin are the more biologically active forms, it may be beneficial to capture both forms of PYY and ghrelin as both forms may be physiologically relevant $[12,23,53]$. Particularly, with regard to PYY, both circulating forms are biologically active and have high affinity for known $\mathrm{Y}$ receptors, i.e. $\mathrm{PYY}_{1-36}$ binds with high affinity to the $\mathrm{Y} 1$ receptor and $\mathrm{PYY}_{3-36}$ binds with high affinity to the Y2 receptor [17]. The conversion of $\mathrm{PYY}_{1-36}$ to $\mathrm{PYY}_{3-36}$ increases the binding affinity of PYY for the Y2 receptor, the actions of which are thought to most affect the suppression of appetite [2]. As with most long-term weight-loss trials, the assessment of dietary intakes in this study is based on self-reported data. Although participants were

Peptides. Author manuscript; available in PMC 2014 November 03. 
instructed on the accurate completion of diet records, which were reviewed by registered dietitians, it is known that such records can have several sources of error [11,31, 57].

\subsection{Conclusions}

In conclusion, during weight loss and maintenance, low-ED diets were associated with lesser increases in circulating concentrations of the hunger hormone ghrelin and higher circulating concentrations of PYY. Reductions in ED may promote weight maintenance after a period of weight loss by suppressing increases in ghrelin in response to an energy deficit that may encourage weight regain, as well as by promoting increases in circulating concentrations of the satiety hormone, PYY.

\section{Acknowledgments}

We thank Julie Ello-Martin, the staff in the Laboratory for the Study of Human Ingestive Behavior at The Pennsylvania State University and the participants for their contributions. Brenna R. Hill is supported by Pennsylvania State University's Intercollegiate Graduate Degree Program in Physiology. The clinical trial was funded by NIH grants R37DK039177 and M01RR10732. The current study was also supported by NIH grants M01 RR 10732 and US DoD PR054531.

\section{References}

1. Adrian TE, Ferri GL, Bacarese-Hamilton AJ, Fuessl HS, Polak JM, Bloom SR. Human distribution and release of a putative new gut hormone, peptide YY. Gastroenterology. 1985; 89:1070-7. [PubMed: 3840109]

2. Ballantyne GH. Peptide YY(1-36) and peptide YY(3-36): Part I. Distribution, release and actions. Obesity surgery. 2006; 16:651-8. [PubMed: 16687037]

3. Bandura A. Health promotion by social cognitive means. Health Educ Behav. 2004; 31:143-64. [PubMed: 15090118]

4. Batterham RL, Heffron H, Kapoor S, Chivers JE, Chandarana K, Herzog H, et al. Critical role for peptide YY in protein-mediated satiation and body-weight regulation. Cell Metab. 2006; 4:223-33. [PubMed: 16950139]

5. Bell EA, Castellanos VH, Pelkman CL, Thorwart ML, Rolls BJ. Energy density of foods affects energy intake in normal-weight women. Am J Clin Nutr. 1998; 67:412-20. [PubMed: 9497184]

6. Bell EA, Rolls BJ. Energy density of foods affects energy intake across multiple levels of fat content in lean and obese women. Am J Clin Nutr. 2001; 73:1010-8. [PubMed: 11382653]

7. Bergmann JF, Chassany O, Petit A, Triki R, Caulin C, Segrestaa JM. Correlation between echographic gastric emptying and appetite: influence of psyllium. Gut. 1992; 33:1042-3. [PubMed: 1398229]

8. Bes-Rastrollo M, van Dam RM, Martinez-Gonzalez MA, Li TY, Sampson LL, Hu FB. Prospective study of dietary energy density and weight gain in women. Am J Clin Nutr. 2008; 88:769-77. [PubMed: 18779295]

9. Brown, HaPR. Applied Mixed Models in Medicine. 2. Chichester: John Wiley \& Sons, Ltd; 2006.

10. Burton-Freeman BM, Keim NL. Glycemic index, cholecystokinin, satiety and disinhibition: is there an unappreciated paradox for overweight women? Int J Obes (Lond). 2008; 32:1647-54. [PubMed: 18825157]

11. Caan B, Ballard-Barbash R, Slattery ML, Pinsky JL, Iber FL, Mateski DJ, et al. Low energy reporting may increase in intervention participants enrolled in dietary intervention trials. $\mathbf{J}$ Am Diet Assoc. 2004; 104:357-66. quiz 491. [PubMed: 14993857]

12. Chelikani PK, Haver AC, Reidelberger RD. Comparison of the inhibitory effects of PYY(3-36) and PYY(1-36) on gastric emptying in rats. Am J Physiol Regul Integr Comp Physiol. 2004; 287:R1064-70. [PubMed: 15242829] 
13. Cummings DE. Ghrelin and the short- and long-term regulation of appetite and body weight. Physiol Behav. 2006; 89:71-84. [PubMed: 16859720]

14. Cummings DE, Purnell JQ, Frayo RS, Schmidova K, Wisse BE, Weigle DS. A preprandial rise in plasma ghrelin levels suggests a role in meal initiation in humans. Diabetes. 2001; 50:1714-9. [PubMed: 11473029]

15. Cummings DE, Weigle DS, Frayo RS, Breen PA, Ma MK, Dellinger EP, et al. Plasma ghrelin levels after diet-induced weight loss or gastric bypass surgery. N Engl J Med. 2002; 346:1623-30. [PubMed: 12023994]

16. Date Y, Kojima M, Hosoda H, Sawaguchi A, Mondal MS, Suganuma T, et al. Ghrelin, a novel growth hormone-releasing acylated peptide, is synthesized in a distinct endocrine cell type in the gastrointestinal tracts of rats and humans. Endocrinology. 2000; 141:4255-61. [PubMed: 11089560]

17. Dumont Y, Fournier A, St-Pierre S, Quirion R. Characterization of neuropeptide Y binding sites in rat brain membrane preparations using [125I][Leu31,Pro34]peptide YY and [125I]peptide YY336 as selective $\mathrm{Y} 1$ and $\mathrm{Y} 2$ radioligands. The Journal of pharmacology and experimental therapeutics. 1995; 272:673-80. [PubMed: 7853181]

18. Edwards LJ, Muller KE, Wolfinger RD, Qaqish BF, Schabenberger O. An R2 statistic for fixed effects in the linear mixed model. Stat Med. 2008; 27:6137-57. [PubMed: 18816511]

19. Ello-Martin JA, Roe LS, Ledikwe JH, Beach AM, Rolls BJ. Dietary energy density in the treatment of obesity: a year-long trial comparing 2 weight-loss diets. Am J Clin Nutr. 2007; 85:1465-77. [PubMed: 17556681]

20. English PJ, Ghatei MA, Malik IA, Bloom SR, Wilding JP. Food fails to suppress ghrelin levels in obese humans. J Clin Endocrinol Metab. 2002; 87:2984. [PubMed: 12050284]

21. Essah PA, Levy JR, Sistrun SN, Kelly SM, Nestler JE. Effect of weight loss by a low-fat diet and a low-carbohydrate diet on peptide YY levels. Int J Obes (Lond). 2010; 34:1239-42. [PubMed: 20351741]

22. Flood JE, Rolls BJ. Soup preloads in a variety of forms reduce meal energy intake. Appetite. 2007; 49:626-34. [PubMed: 17574705]

23. Foster-Schubert KE, Overduin J, Prudom CE, Liu J, Callahan HS, Gaylinn BD, et al. Acyl and total ghrelin are suppressed strongly by ingested proteins, weakly by lipids, and biphasically by carbohydrates. J Clin Endocrinol Metab. 2008; 93:1971-9. [PubMed: 18198223]

24. Greene LF, Malpede CZ, Henson CS, Hubbert KA, Heimburger DC, Ard JD. Weight maintenance 2 years after participation in a weight loss program promoting low-energy density foods. Obesity (Silver Spring). 2006; 14:1795-801. [PubMed: 17062810]

25. Hansen TK, Dall R, Hosoda H, Kojima M, Kangawa K, Christiansen JS, et al. Weight loss increases circulating levels of ghrelin in human obesity. Clin Endocrinol (Oxf). 2002; 56:203-6. [PubMed: 11874411]

26. Helou N, Obeid O, Azar ST, Hwalla N. Variation of postprandial PYY 3-36 response following ingestion of differing macronutrient meals in obese females. Ann Nutr Metab. 2008; 52:188-95. [PubMed: 18544972]

27. Hill BR, De Souza MJ, Williams NI. Characterization of the diurnal rhythm of peptide YY and its association with energy balance parameters in normal-weight premenopausal women. American journal of physiology Endocrinology and metabolism. 2011; 301:E409-15. [PubMed: 21610227]

28. Jones TE, Basilio JL, Brophy PM, McCammon MR, Hickner RC. Long-term exercise training in overweight adolescents improves plasma peptide YY and resistin. Obesity (Silver Spring). 2009; 17:1189-95. [PubMed: 19247279]

29. Karl JP, Young AJ, Rood JC, Montain SJ. Independent and combined effects of eating rate and energy density on energy intake, appetite, and gut hormones. Obesity. 2013; 21:E244-52. [PubMed: 23592679]

30. Kojima M, Hosoda H, Date Y, Nakazato M, Matsuo H, Kangawa K. Ghrelin is a growth-hormonereleasing acylated peptide from stomach. Nature. 1999; 402:656-60. [PubMed: 10604470]

31. Kristal AR, Andrilla CH, Koepsell TD, Diehr PH, Cheadle A. Dietary assessment instruments are susceptible to intervention-associated response set bias. J Am Diet Assoc. 1998; 98:40-3. [PubMed: 9434649] 
32. Langlois F, Langlois MF, Carpentier AC, Brown C, Lemieux S, Hivert MF. Ghrelin levels are associated with hunger as measured by the Three-Factor Eating Questionnaire in healthy young adults. Physiol Behav. 2011; 104:373-7. [PubMed: 21536060]

33. le Roux CW, Aylwin SJ, Batterham RL, Borg CM, Coyle F, Prasad V, et al. Gut hormone profiles following bariatric surgery favor an anorectic state, facilitate weight loss, and improve metabolic parameters. Ann Surg. 2006; 243:108-14. [PubMed: 16371744]

34. le Roux CW, Batterham RL, Aylwin SJ, Patterson M, Borg CM, Wynne KJ, et al. Attenuated peptide YY release in obese subjects is associated with reduced satiety. Endocrinology. 2006; 147:3-8. [PubMed: 16166213]

35. Ledikwe JH, Blanck HM, Khan LK, Serdula MK, Seymour JD, Tohill BC, et al. Dietary energy density determined by eight calculation methods in a nationally representative United States population. J Nutr. 2005; 135:273-8. [PubMed: 15671225]

36. Ledikwe JH, Rolls BJ, Smiciklas-Wright H, Mitchell DC, Ard JD, Champagne C, et al. Reductions in dietary energy density are associated with weight loss in overweight and obese participants in the PREMIER trial. Am J Clin Nutr. 2007; 85:1212-21. [PubMed: 17490955]

37. Leidy HJ, Dougherty KA, Frye BR, Duke KM, Williams NI. Twenty-four-hour ghrelin is elevated after calorie restriction and exercise training in non-obese women. Obesity (Silver Spring). 2007; 15:446-55. [PubMed: 17299118]

38. Leidy HJ, Gardner JK, Frye BR, Snook ML, Schuchert MK, Richard EL, et al. Circulating ghrelin is sensitive to changes in body weight during a diet and exercise program in normal-weight young women. J Clin Endocrinol Metab. 2004; 89:2659-64. [PubMed: 15181038]

39. Luoto R, Kaprio J, Uutela A. Age at natural menopause and sociodemographic status in Finland. Am J Epidemiol. 1994; 139:64-76. [PubMed: 8296776]

40. MacIntosh CG, Andrews JM, Jones KL, Wishart JM, Morris HA, Jansen JB, et al. Effects of age on concentrations of plasma cholecystokinin, glucagon-like peptide 1, and peptide YY and their relation to appetite and pyloric motility. The American journal of clinical nutrition. 1999; 69:9991006. [PubMed: 10232642]

41. Martins C, Robertson MD, Morgan LM. Impact of restraint and disinhibition on PYY plasma levels and subjective feelings of appetite. Appetite. 2010; 55:208-13. [PubMed: 20541573]

42. McKinlay SM, Bifano NL, McKinlay JB. Smoking and age at menopause in women. Ann Intern Med. 1985; 103:350-6. [PubMed: 4026083]

43. Nakazato M, Murakami N, Date Y, Kojima M, Matsuo H, Kangawa K, et al. A role for ghrelin in the central regulation of feeding. Nature. 2001; 409:194-8. [PubMed: 11196643]

44. Nedvidkova J, Krykorkova I, Bartak V, Papezova H, Gold PW, Alesci S, et al. Loss of mealinduced decrease in plasma ghrelin levels in patients with anorexia nervosa. The Journal of clinical endocrinology and metabolism. 2003; 88:1678-82. [PubMed: 12679456]

45. Perez-Escamilla R, Obbagy JE, Altman JM, Essery EV, McGrane MM, Wong YP, et al. Dietary energy density and body weight in adults and children: a systematic review. J Acad Nutr Diet. 2012; 112:671-84. [PubMed: 22480489]

46. Pfluger PT, Kampe J, Castaneda TR, Vahl T, D'Alessio DA, Kruthaupt T, et al. Effect of human body weight changes on circulating levels of peptide YY and peptide YY3-36. J Clin Endocrinol Metab. 2007; 92:583-8. [PubMed: 17119001]

47. Rolls BJ. The relationship between dietary energy density and energy intake. Physiol Behav. 2009; 97:609-15. [PubMed: 19303887]

48. Rolls BJ, Castellanos VH, Halford JC, Kilara A, Panyam D, Pelkman CL, et al. Volume of food consumed affects satiety in men. Am J Clin Nutr. 1998; 67:1170-7. [PubMed: 9625090]

49. Roth CL, Enriori PJ, Harz K, Woelfle J, Cowley MA, Reinehr T. Peptide YY is a regulator of energy homeostasis in obese children before and after weight loss. J Clin Endocrinol Metab. 2005; 90:6386-91. [PubMed: 16204364]

50. Scheid, JL.; Birch, LL.; Williams, NI.; De Souza, MJ. Dietary cognitive restraint is related to peptide YY concentrations in young college-aged women. Unpublished

51. Scheid JL, De Souza MJ, Leidy HJ, Williams NI. Ghrelin but not peptide YY is related to change in body weight and energy availability. Medicine and science in sports and exercise. 2011; 43:2063-71. [PubMed: 21502892] 
52. Schur EA, Cummings DE, Callahan HS, Foster-Schubert KE. Association of cognitive restraint with ghrelin, leptin, and insulin levels in subjects who are not weight-reduced. Physiol Behav. 2008; 93:706-12. [PubMed: 18164043]

53. Sloth B, Holst JJ, Flint A, Gregersen NT, Astrup A. Effects of PYY1-36 and PYY3-36 on appetite, energy intake, energy expenditure, glucose and fat metabolism in obese and lean subjects. Am J Physiol Endocrinol Metab. 2007; 292:E1062-8. [PubMed: 17148749]

54. Stunkard AJ, Messick S. The three-factor eating questionnaire to measure dietary restraint, disinhibition and hunger. J Psychosom Res. 1985; 29:71-83. [PubMed: 3981480]

55. Sumithran P, Prendergast LA, Delbridge E, Purcell K, Shulkes A, Kriketos A, et al. Long-term persistence of hormonal adaptations to weight loss. N Engl J Med. 2011; 365:1597-604. [PubMed: 22029981]

56. Taylor IL. Role of peptide YY in the endocrine control of digestion. J Dairy Sci. 1993; 76:2094101. [PubMed: 8345132]

57. Trabulsi J, Schoeller DA. Evaluation of dietary assessment instruments against doubly labeled water, a biomarker of habitual energy intake. Am J Physiol Endocrinol Metab. 2001; 281:E891-9. [PubMed: 11595643]

58. Tschop M, Weyer C, Tataranni PA, Devanarayan V, Ravussin E, Heiman ML. Circulating ghrelin levels are decreased in human obesity. Diabetes. 2001; 50:707-9. [PubMed: 11289032]

59. Williams DL, Cummings DE, Grill HJ, Kaplan JM. Meal-related ghrelin suppression requires postgastric feedback. Endocrinology. 2003; 144:2765-7. [PubMed: 12810528] 


\section{Highlights}

- Ghrelin and PYY increased in response to reduced ED and consequent weight loss

- Low-ED diets were associated with lesser increases ghrelin across the intervention

- Low-ED diets tended to be associated with increases in PYY

- Reductions in ED may promote weight loss by blunting orexigenic hormone responses 
A

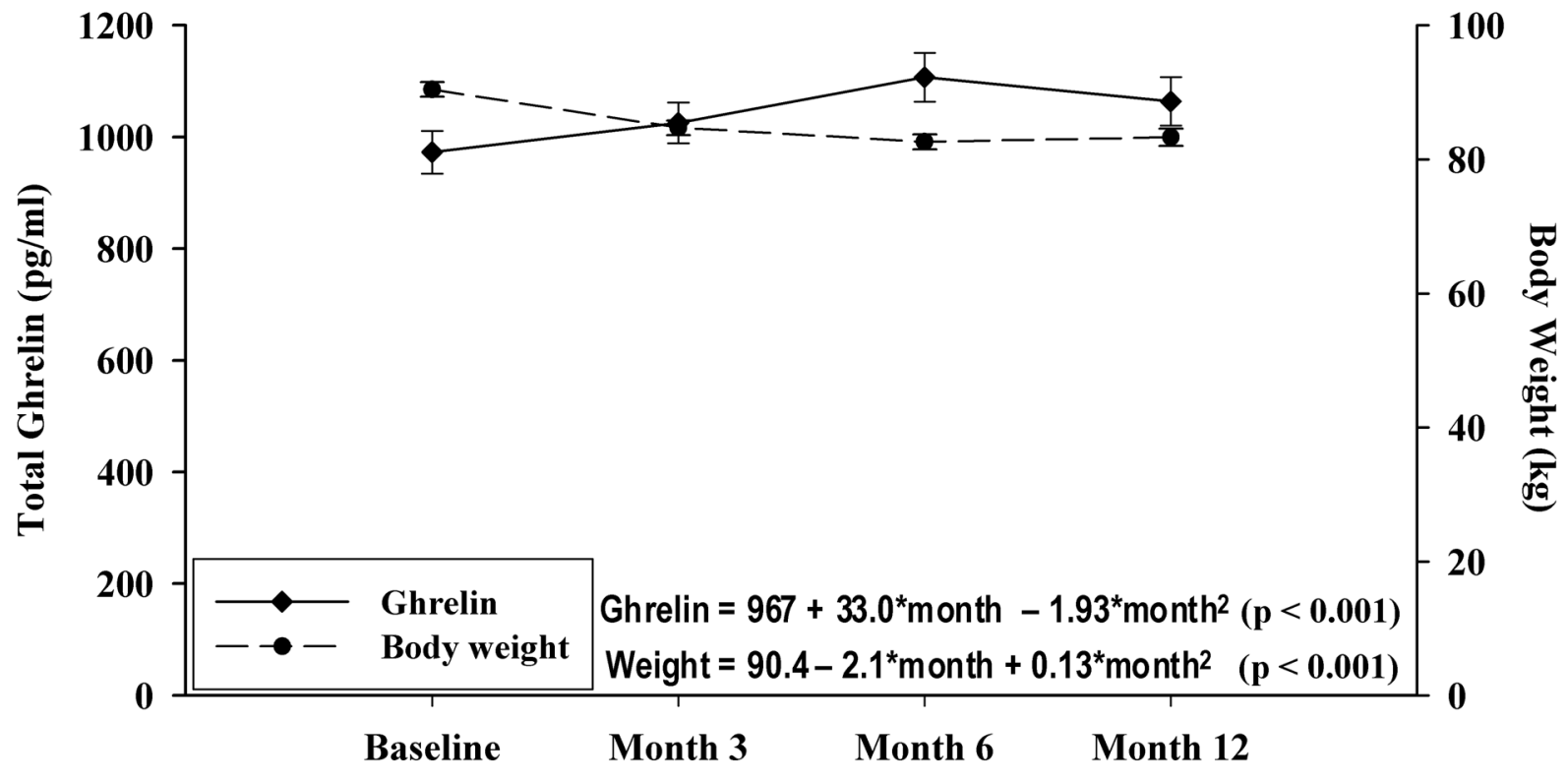

B

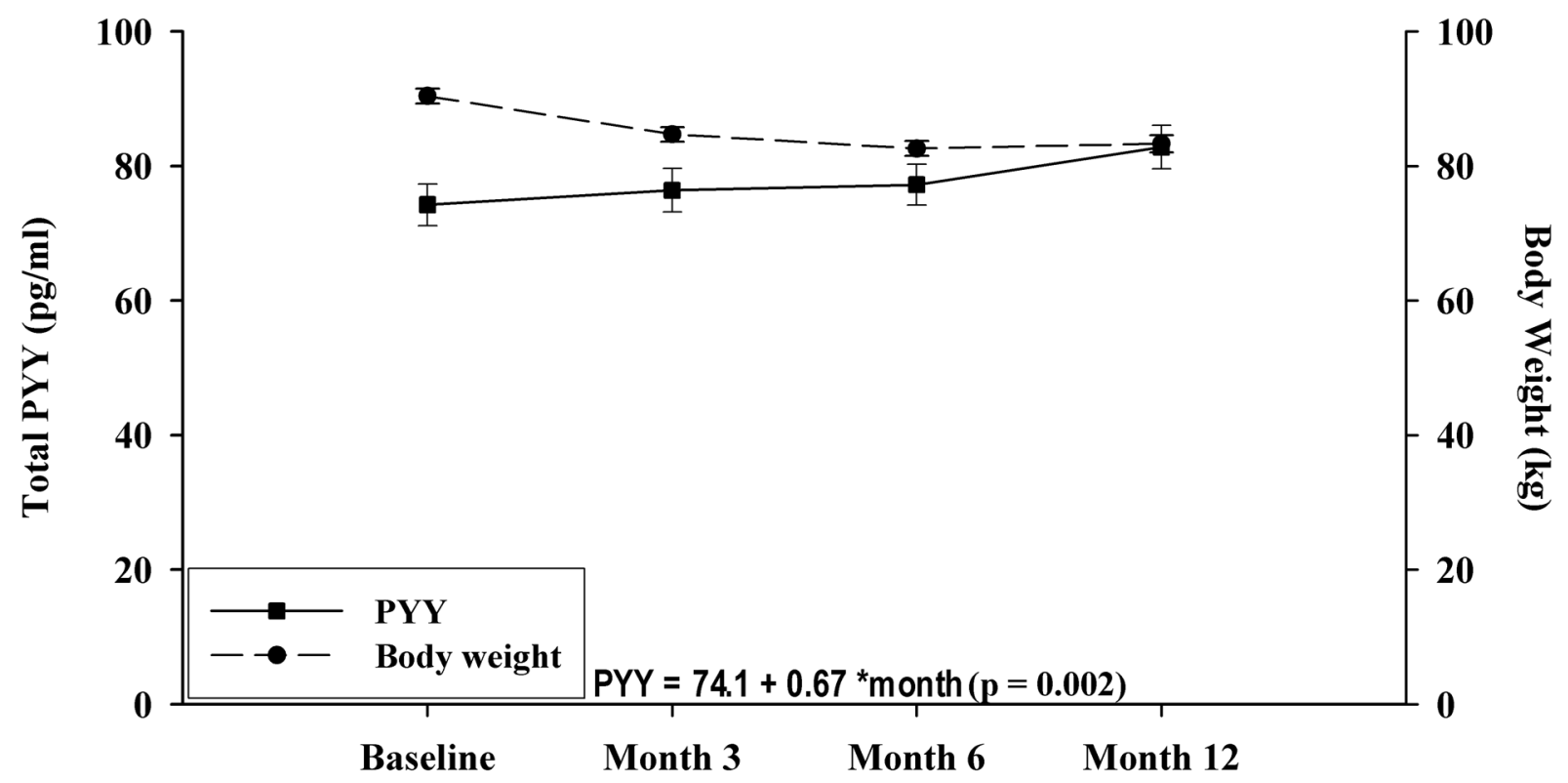

Figure 1.

Results of linear mixed modeling demonstrating change in fasting concentrations and body weight from month 0 to months 3, 6 and 12 of the intervention. A. Fasting ghrelin (pg/ml) vs. body weight $(\mathrm{kg})$ B. Fasting PYY (pg/ml) vs. body weight $(\mathrm{kg})$. Results are reported as mean \pm SEM. 


\section{Table 1}

Subject characteristics at month 0

\begin{tabular}{lrc}
\hline Variable & Mean \pm SEM & Range \\
\hline Age $(\mathrm{y})$ & $46.7 \pm 1.0$ & $22.2-60.4$ \\
Height $(\mathrm{cm})$ & $164.7 \pm 0.6$ & $153.5-183.0$ \\
Body Weight $(\mathrm{kg})$ & $90.4 \pm 1.1$ & $73.0-122.0$ \\
BMI $\left(\mathrm{kg} / \mathrm{m}^{2}\right)$ & $33.3 \pm 0.3$ & $29.6-40.4$ \\
Body Fat $(\%)$ & $39.0 \pm 0.3$ & $32.3-44.7$ \\
Body Fat $(\mathrm{kg})$ & $35.4 \pm 0.6$ & $24.8-53.4$ \\
Lean Body Mass $(\mathrm{kg})$ & $55.0 \pm 0.6$ & $45.2-68.8$ \\
Restraint Score $^{a}$ & $9.2 \pm 0.4$ & $2-19$ \\
Hunger Score $^{a}$ & $6.1 \pm 0.4$ & $0-14$ \\
Disinhibition Score $^{a}$ & $9.9 \pm 0.4$ & $2-16$ \\
\hline
\end{tabular}

${ }^{a}$ Eating Inventory Scores (Stunkard 1985). n = 71 
Table 2

Energy intake, body composition and Eating Inventory scores across the intervention

\begin{tabular}{|c|c|c|c|c|}
\hline Variable & Month 0 & Month 3 & Month 6 & Month 12 \\
\hline \multicolumn{5}{|l|}{ Energy Intake } \\
\hline Energy (kcal/d) & $1886 \pm 51$ & $1366 \pm 43^{a}$ & $1351 \pm 41^{a}$ & $1371 \pm 43^{a}$ \\
\hline Energy $(\mathrm{kJ} / \mathrm{d})$ & $7891 \pm 213$ & $5715 \pm 180^{a}$ & $5653 \pm 172^{a}$ & $5736 \pm 180^{a}$ \\
\hline Food Weight (g) & $3055 \pm 82$ & $2721 \pm 94^{a}$ & $2711 \pm 91^{a}$ & $2774 \pm 110^{a}$ \\
\hline Energy Density (kcal/g) & $1.80 \pm 0.04$ & $1.31 \pm 0.04^{a}$ & $1.33 \pm 0.05^{a}$ & $1.41 \pm 0.04^{a=}$ \\
\hline Energy Density $(\mathrm{kJ} / \mathrm{g})$ & $7.53 \pm 0.17$ & $5.48 \pm 0.17^{a}$ & $5.56 \pm 0.21^{a}$ & $5.90 \pm 0.17^{a}$ \\
\hline \multicolumn{5}{|l|}{ Body Composition } \\
\hline Body Weight (kg) & $90.4 \pm 1.1$ & $84.7 \pm 1.1^{a}$ & $82.6 \pm 1.1^{a b}$ & $83.3 \pm 1.3^{a b c}$ \\
\hline BMI $\left(\mathrm{kg} / \mathrm{m}^{2}\right)$ & $33.3 \pm 0.3$ & $31.2 \pm 0.3^{a}$ & $30.4 \pm 0.3^{a b}$ & $30.7 \pm 0.4^{a b}$ \\
\hline Body Fat $(\%)$ & $39.0 \pm 0.3$ & $37.3 \pm 0.3^{a}$ & $36.0 \pm 0.4^{a b}$ & $36.4 \pm 0.4^{a b}$ \\
\hline Body Fat $(\mathrm{kg})$ & $35.4 \pm 0.6$ & $31.8 \pm 0.6^{a}$ & $30.0 \pm 0.7 a b$ & $30.6 \pm 0.8^{a b}$ \\
\hline Lean Body Mass (kg) & $55.0 \pm 0.6$ & $52.9 \pm 0.6^{a}$ & $52.6 \pm 0.6^{a}$ & $52.7 \pm 0.6^{a}$ \\
\hline Weight Lost (kg) & ---------- & $5.7 \pm 0.4^{a}$ & $7.8 \pm 0.5^{a b}$ & $7.1 \pm 0.7^{a b}$ \\
\hline \multicolumn{5}{|l|}{ Eating Inventory } \\
\hline Restraint Score & $9.2 \pm 0.4^{\mathrm{iiiiiii}}$ & ---------- & $14.9 \pm 0.4^{a}$ & $14.4 \pm 0.4^{a}$ \\
\hline Hunger Score & $6.1 \pm 0.4$ & --------- & $4.3 \pm 0.3^{a}$ & $4.4 \pm 0.3^{a}$ \\
\hline Disinhibition Score & $9.9 \pm 0.4$ & ---------- & $7.2 \pm 0.3^{a}$ & $7.4 \pm 0.4^{a}$ \\
\hline \multicolumn{5}{|l|}{ VAS Scores } \\
\hline Hunger $3 \mathrm{~d}$ mean & $51.1 \pm 1.9$ & $50.9 \pm 2.1$ & $48.0 \pm 2.2$ & $52.5 \pm 2.3^{c}$ \\
\hline Hunger AUC & $486.4 \pm 19.5$ & $460.0 \pm 16.7$ & $467.0 \pm 20.8$ & $496.2 \pm 20.3$ \\
\hline Fullness $3 \mathrm{~d}$ mean & $62.0 \pm 1.9$ & $64.1 \pm 1.9$ & $62.6 \pm 2.0$ & $57.8 \pm 2.1$ \\
\hline Fullness AUC & $536.0 \pm 19.8$ & $533.5 \pm 18.0$ & $538.6 \pm 20.4$ & $515.1 \pm 17.9$ \\
\hline
\end{tabular}

Data are reported as Mean $\pm \mathrm{SEM}, \mathrm{n}=71$.

${ }^{a}$ Significant difference from baseline $(\mathrm{p}<0.05)$,

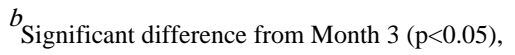




